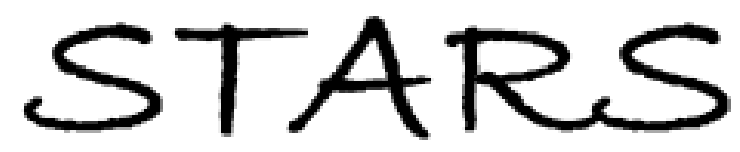

University of Central Florida

STARS

$1-1-2012$

\title{
Scenes from the Past Multidetector CT of Egyptian Mummies of the Redpath Museum
}

Andrew D. Wade

Gregory J. Garvin

Jaana $\mathrm{H}$. Hurnanen

Lana Williams

University of Central Florida

Barbara Lawson

See next page for additional authors

Find similar works at: https://stars.library.ucf.edu/facultybib2010

University of Central Florida Libraries http://library.ucf.edu

This Article is brought to you for free and open access by the Faculty Bibliography at STARS. It has been accepted for inclusion in Faculty Bibliography 2010 s by an authorized administrator of STARS. For more information, please contactSTARS@ucf.edu.

\section{Recommended Citation}

Wade, Andrew D.; Garvin, Gregory J.; Hurnanen, Jaana H.; Williams, Lana; Lawson, Barbara; Nelson, Andrew J.; and Tampieri, Donatella, "Scenes from the Past Multidetector CT of Egyptian Mummies of the Redpath Museum" (2012). Faculty Bibliography 2010s. 3449.

https://stars.library.ucf.edu/facultybib2010/3449

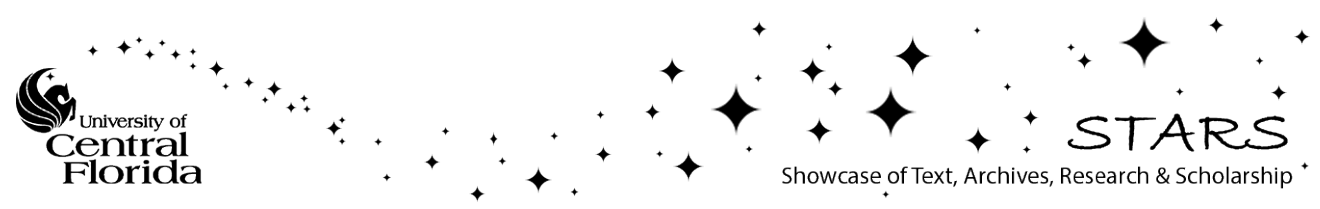




\section{Authors}

Andrew D. Wade, Gregory J. Garvin, Jaana H. Hurnanen, Lana Williams, Barbara Lawson, Andrew J. Nelson, and Donatella Tampieri 


\section{Scenes from the Past}

\section{Multidetector CT of Egyptian Mummies of the Redpath Museum ${ }^{1}$}

TEACHING

POINTS

See last page

\begin{abstract}
Andrew D. Wade, PhD • Gregory F. Garvin, MD • Faana H. Hurnanen, LicD Lana Williams, PhD • Barbara Lawson, $M A \cdot$ Andrew F. Nelson, PhD Donatella Tampieri, MD, FRCP(C)
\end{abstract}

As a nondestructive method of historical and anthropologic inquiry, imaging has played an important role in mummy studies over the past several decades. Recent technologic advances have made multidetector computed tomography (CT) an especially useful means for deepening the present understanding of ancient cultures by examining preserved human remains. In April 2011, three ancient Egyptian human mummies from the Redpath Museum of McGill University were examined with 320-section multidetector CT as part of the IMPACT Radiological Mummy Database project headquartered at the University of Western Ontario. Whole-body scanning was performed with a section thickness of $0.5 \mathrm{~mm}$ and a peak voltage of $120 \mathrm{kVp}$, and the raw CT datasets were postprocessed by using smooth body and high-resolution bone convolution filters. Two of the mummies were scanned at different energy levels (80 and $135 \mathrm{keV}$ ). The high-resolution CT scans revealed the details of mummification and allowed observations about the socioeconomic and health status of the human subjects based on both the mummification technique used and the appearance of the remains, particularly the bones and teeth. The paleopathologic information obtained from the scans confirmed some findings in studies performed in the same mummies in the late 19th and 20th centuries. The CT scans also demonstrated a high degree of variability in Egyptian mortuary practice, variability that is not generally recognized in the literature. Unusual features that were observed included a relatively uncommon retained heart in mummy RM2718, retained lungs in a mummy from which the heart had been extracted (RM2720), and a cartonnage plaque placed over the left abdomen of a mummy that had been eviscerated transperineally (RM2717).

${ }^{\circ}$ RSNA, $2012 \cdot$ radiographics.rsna.org 


\section{Introduction}

Computed tomography (CT) has been applied to the study of mummified human remains from the late 1970 s to the present $(1,2)$. The latest generation of clinical multidetector CT scanners provides researchers with the capability to efficiently perform full-body CT with isotropic submillimeter resolution and acquire identical scans at different energy levels (3). Thus, multidetector CT has become an important method for studying mummified human remains. The present article describes the findings at multidetector CT in three Egyptian human mummies that were not previously well described.

The results of recent studies based on the Internet-based Mummy Picture Archive and Communication Technology (IMPACT) Radiological Mummy Database at the University of Western Ontario $(4,5)$ have underscored the importance of considering ancient Egyptian mummification techniques within a comparative context. The IMPACT Database, which consists of detailed descriptions and imaging studies in Digital Imaging and Communications in Medicine (DICOM) format, relies on contributions from interdisciplinary teams of scientific investigators and is designed to facilitate large-scale comparative studies based on primary data acquired with radiologic imaging. As evidence of wide variability in techniques has emerged from such studies, the account of mummification given in Herodotus's History (ca. $440 \mathrm{BC}$ ) has been shown to be simplistic and incomplete.

In late April 2011, the authors examined three human mummies from the Redpath Museum of McGill University (RM2717, RM2718, and RM2720) by using a 320-section multidetector CT scanner located at the Montreal Neurological Institute and Hospital. These examinations produced whole-body high-resolution CT datasets for two previously unscanned mummies and a new dataset at higher resolution for a mummy (RM2718) that was scanned in 1995 at a section thickness of $3 \mathrm{~mm}$. The isotropic submillimeter imaging datasets acquired in the more recent CT examinations allow three-dimensional (3D) reconstruction for viewing in any plane, making it unlikely that repeat scans of these same mummies will be necessary in the near future.
These CT examinations were performed to help advance research into the variability of Egyptian mummification traditions over time and Point the sociopolitical forces driving the changes in ancient Egyptian mortuary ideology, as well as to validate findings in previous studies of these mummies. Nondestructive examinations of mummies shed light on chronologic changes in mortuary ritual and interactions between the factors of sex, status, politics, and mummification, while allowing preservation of these historical artifacts for future researchers.

\section{CT Study Methods}

All the mummies were scanned by using the smallest section thickness available on the scanner (Aquilion One; Toshiba, Tustin, Calif), that is, $0.5 \mathrm{~mm}$. The raw CT datasets were helically acquired at $120 \mathrm{kV}$ and preprocessed by using the convolution filters FC02 for smooth body (which includes correction for beam hardening) and FC81 for high-resolution bone. RM2718 and RM2720 were also scanned at $80 \mathrm{kV}$ and $135 \mathrm{kV}$ to permit the use of dual-energy or multiple-energy postprocessing techniques. Localized scanning of the head, chest, and abdomen of both mummies, and in addition, the face mask of RM2720, was performed. RM2717 was scanned in its coffin with the lid removed. The scans were examined by using the workstation provided by the scanner manufacturer and two special reconstruction software programs (Vitrea, Vital Images, Minnetonka, Minn; and OsiriX, Pixmeo SARL, Bernex, Switzerland).

\section{Study Sample}

\section{Theban Female (RM2717)}

This mummy was brought to Montreal from Thebes by James Ferrier sometime before 1859 (6). A note in the museum file relating to the artifact states that it dates from the 18th Dynasty (7). A committee of the Natural History Society that performed a partial unwrapping (head and feet) of the mummy reported that the shape of the face and body had been enhanced to some degree by lichen and ground spices, which had been applied to the anterior surface before wrapping (6). A square sheet of copper foil positioned over the face and two smaller pieces on the tops of the feet also were noted. Short, straight white hair, the strands of which appeared flat oval in cross section, was found on the uncovered head. The report also mentioned that the right index finger and left little finger had been cut 
off, "probably to obtain rings" (6, p 402). A radiographic examination performed at the Royal Victoria Hospital in 1979 confirmed the absence of the two fingers. On the basis of the shape of the pelvis and the sternal rib ends, the examining physician, Simon Braun, determined that the mummy was a woman. Narrowing of the intervertebral spaces and hip and knee joint spaces and calcification of the intervertebral disks and knee meniscal cartilage provided evidence of an advanced age at death $(7,8)$. New and largely inaccurate findings in the 1979 examination included the absence of the brain, which was believed to be indicated by broken paranasal bones, and the presence of an intact heart.

\section{Theban Male (RM2718)}

This mummy was brought to Montreal by James Ferrier at the same time as RM2717. A committee of the Natural History Society, which examined the unwrapped mummy, reported that no spices were found on the body surface but that the mummy's head "has been in part covered with bitumen, as if this had been poured upon it or into its cavities, and had in part run over the surface" $(6, \mathrm{p}$ 403). Such a treatment is consistent with the instructions for the Ritual of Embalmment, as recorded in a Roman-era papyrus (9). The committee noted that the eyes had been extracted and the eyelids molded to look natural, and that the scalp retained an "abundance of straight brown hair” (6, p 403).

In a subsequent radiologic imaging report, the mummy was described as a poorly preserved 35-year-old man belonging to the lower classes. This characterization was probably occasioned by the absence of a coffin or cartonnage and the presence of an intact nose (and, by implication, brain), findings that were believed to signify incomplete embalmment (7).

In January 1995, the mummy was examined by radiologist Étienne Cardinal and paleopathologist Patrick Horne, who reviewed radiographs and CT scans obtained at the Hôpital Saint-Luc, Montreal, Quebec (Cardinal et al, unpublished manuscript, 1996; 10). Their report stated that the subject had been excerebrated via the left nostril and eviscerated via a transabdominal incision. Although the lungs and abdominal organs were absent, the heart was retained. The presence of a penis and a narrow subpubic angle confirmed that the sex was male. On the basis of epiphyseal union and the extent of dental wear, the age at death was estimated to be 30-35 years.

An undated report based on a dental analysis performed by Odin Langsioen of the University of Minnesota-Duluth School of Medicine described dental attrition and subsequent caries with resultant "abscess formation and fistulous drainage of purulent material into the oral cavity" (11).

\section{Ptolemaic Female (RM2720)}

A note in the McGill University archives dating from 1904 indicates that RM2720 is a female mummy of unknown age that was found "in a tomb or pit in the solid rock at Hawara-elMaktaa, and about 150 yds from the Pyramid of Amun-am-hat [Amenemhat III]" (RG 41, L 4). The mummy was donated to the university by Sir Thomas Roddick in May 1895 . Findings at radiography, which was initially performed in 1929 , indicated that RM2720 was a young girl with excellent teeth and that the mummy's mask and wrappings were undisturbed (7). When RM2720 was examined again with radiography in 1979 (8), the mummy was found to be a woman between the ages of 21 and 40 years. The pattern of the wig and other features painted on her mask, along with her crossed arms, indicated that the mummy belonged to the Ptolemaic or Roman period. The nature of an oval object between her thighs was disputed, with arguments presented for a papyrus roll, linen bundle, and viscera packet $(7,8,12)$.

\section{CT Findings}

\section{Mummification of RM2717}

RM2717 was mummified anthropogenically (ie, through human intervention) and wrapped in linen, with a narrow wooden board $17.4 \mathrm{~cm}$ wide, $2.0 \mathrm{~cm}$ thick, and $167.2 \mathrm{~cm}$ long (attenuation range, -400 to $100 \mathrm{HU}$ ) placed at her back, within the wrappings. The board was rounded on the dependent side and had a large dovetail at the foot end with a wooden peg $3.9 \mathrm{~cm}$ long, $8.5 \mathrm{~mm}$ in diameter (attenuation range, -250 to $1 \mathrm{HU}$ ) projecting anteriorly from the middle of the base (Fig 1). The arms of RM2717 were extended inferiorly, and her hands were placed palms down on the anterolateral aspect of the thighs. Neither her legs nor her arms were individually wrapped. 


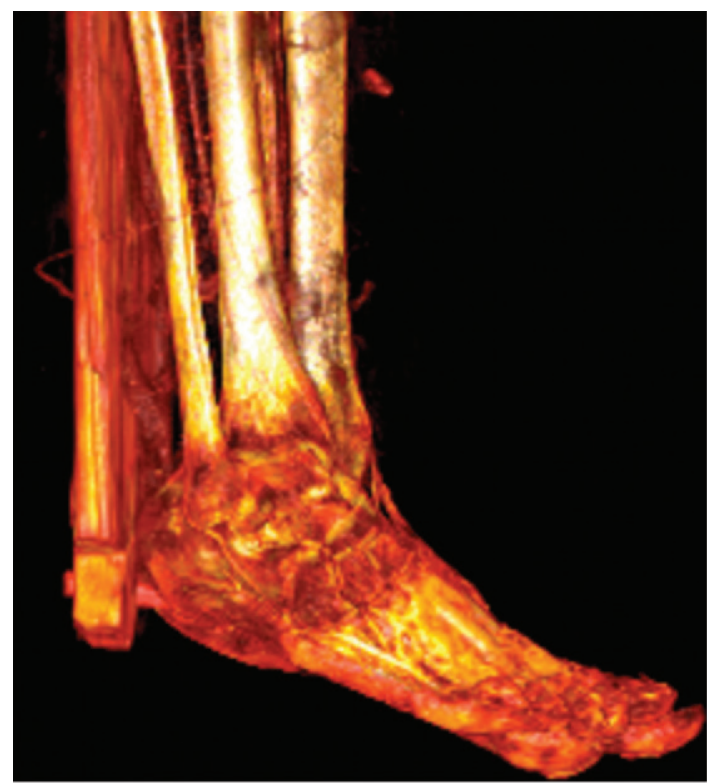

a.

Figure 1. Lateral (a), inferior oblique (b), and posterior (c) 3D images from multidetector CT of RM2717 show the caudal end of a wooden board to which the mummy was attached by its wrappings.

The mummy's brain was intact and appeared as a low-attenuation (range, -200 to $50 \mathrm{HU}$ ), slightly heterogeneous mass in the dependent portion of the cranium (Fig 2a). The brain had not retained much of its original shape, and few if any sulci and gyri were apparent. The dural sheath of the spinal cord was contiguous with the dura mater of the cranial cavity, and there was no apparent damage to the paranasal structures. The eyes remained intact in their orbits. The mouth was packed with a bundle of resin-soaked linen with inclusions that had high attenuation (2300 $\mathrm{HU})$ suggestive of natron or myrrh.

RM2717 was apparently eviscerated through a large defect in the perineal region (Fig 2b). Whether this defect was the result of a perineal incision or an anal or vaginal extraction that extended beyond its natural borders was unclear; however, the single large perineal plug of resin and linen could indicate that the perineal defect was intentionally created by the embalmer.

The heart and lungs were absent from the thoracic cavity, and the pericardium and trachea were displaced toward the right side. Because the right hemidiaphragm was intact and the left hemidiaphragm was excised, it seems likely that the extraction of all three organs sequentially

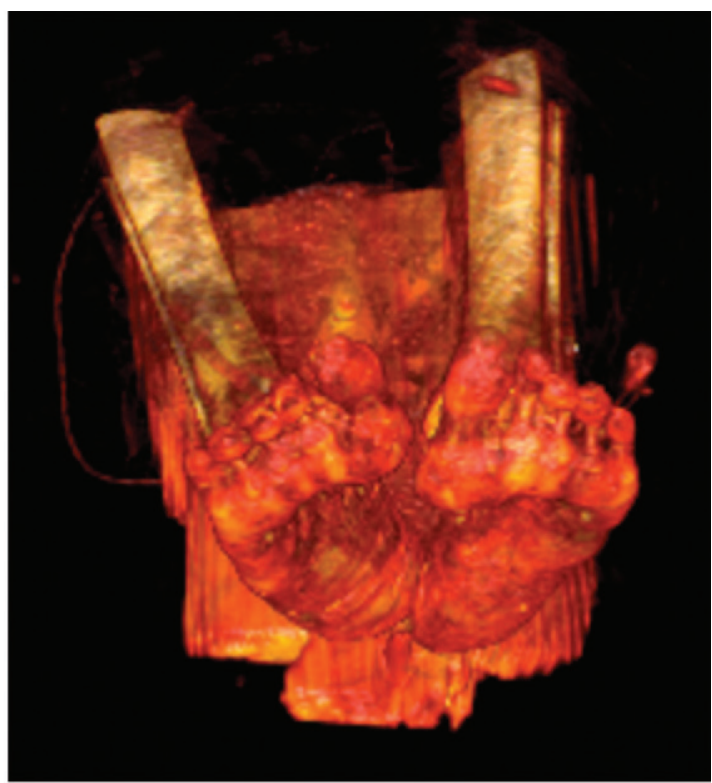

b.

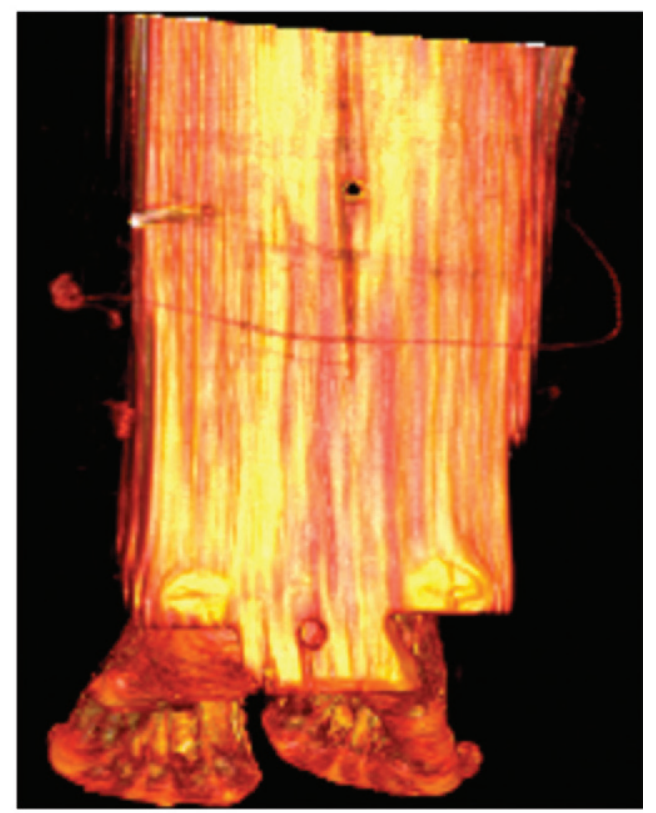

c.

from left to right caused the tracheal and pericardial displacement. The stomach, intestines, liver, and urinary bladder were absent from the abdominal cavity. The left kidney appeared intact in the retroperitoneal space, but the right kidney was not apparent on CT scans. A heterogeneous mass with overall intermediate attenuation (range, 50-100 HU) that contained tiny highattenuation inclusions was apparent in the dependent portion of the right upper abdomen and likely represented resin-soaked linen with adherent natron particles. 


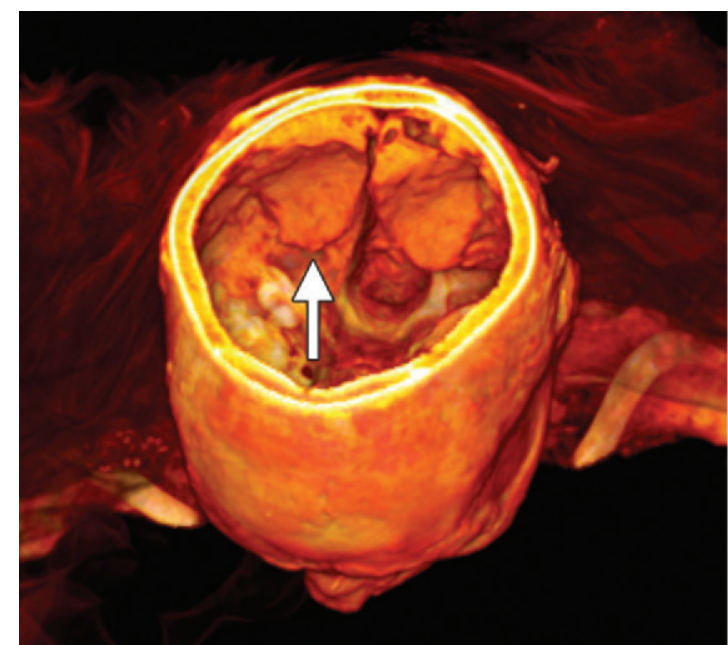

a.

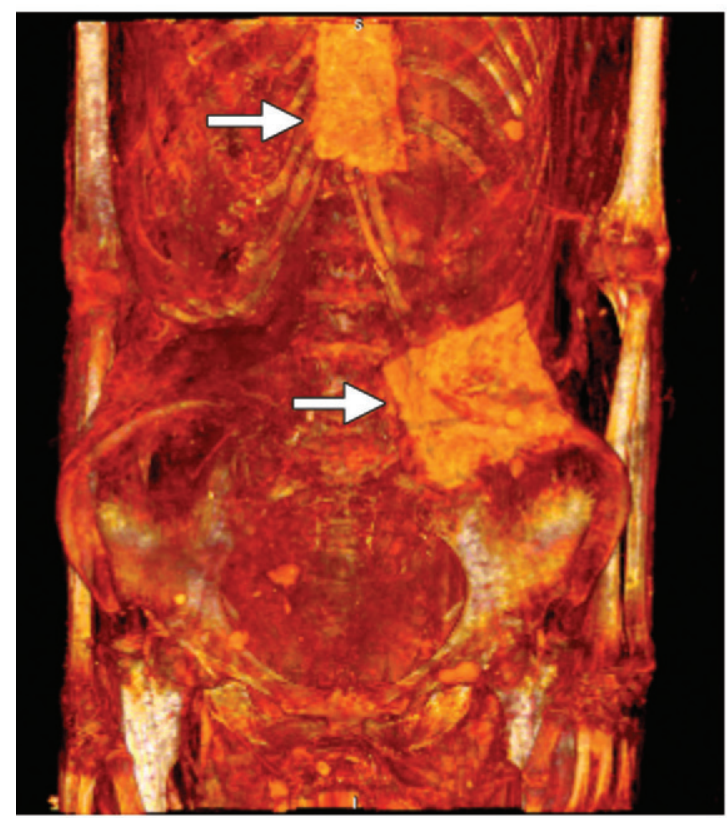

b.

The mummy was tightly wrapped, with resultant compression of the thoracic cavity to the extent that the ribs angled sharply in an inferior direction and some cracking of the costal cartilage had occurred, particularly at the junctions of the cartilage with the floating ribs. Rectangular plaques with intermediate attenuation $(175 \mathrm{HU})$ and a thickness of approximately $4 \mathrm{~mm}$ had been placed over the sternum $(8.56 \mathrm{~cm}$ in the superoinferior dimension and $4.52 \mathrm{~cm}$ in the mediolateral dimension) and left abdomen $(7.05 \mathrm{~cm}$ in the superoinferior dimension and $8.54 \mathrm{~cm}$ in the mediolateral dimension) (Fig 2c). The wrappings had been removed from the head and feet, and a modern pin was apparent where the wrappings

c.

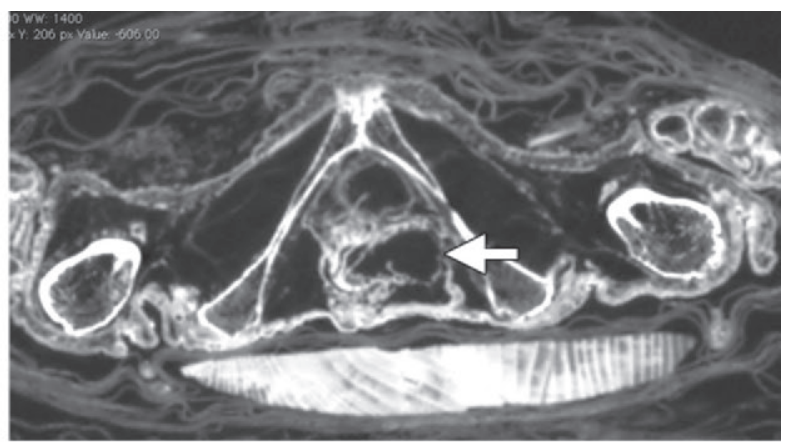

Figure 2. (a, b) Oblique superoinferior (a) and anterior (b) 3D images from multidetector CT of RM2717 show an intact brain (arrow in a) and cartonnage plaques (arrows in b). (c) Axial CT image shows a transperineal evisceration defect (arrow).

ended, above the left shoulder. The wrappings on the torso, arms, and legs, which were intact, were secured in place by cloth bands with a serpentine weave that had been placed in a crisscross pattern over the outermost layer of wrappings. Linen with woven fringes was found among the wrappings, and a dense tassel or beaded fringe was noted in the wrappings between the calves. Several small, thin, branching twigs with lengths ranging from 2 to $5 \mathrm{~cm}$ were found inside the wrappings above the left hand, at the right pubis, and between the thighs.

\section{Mummification of RM2718}

RM2718 was mummified anthropogenically and wrapped in three successive levels of linen bandages, with a layer of resin or plaster between them, from the shoulders to the midcalf. His arms were extended inferiorly, with both hands placed palm downward on the anterolateral aspect of the thighs. Neither the legs nor the arms were wrapped individually, and the arms were not separated from the body by bundled linen.

The brain was absent, as were the dural membranes (including the falx cerebri and tentorium cerebelli) and the dural sheath of the spinal cord superior to the C3 vertebral body. The brain had been removed via a nearly vertical transnasal craniotomy through the left ethmoid air cells (Fig 3a). Only the left ethmoid bone and the left superior nasal concha were damaged. The eyes remained intact within the orbits. The cranial cavity and the naso-orohypopharynx contained no packing material or resin. 


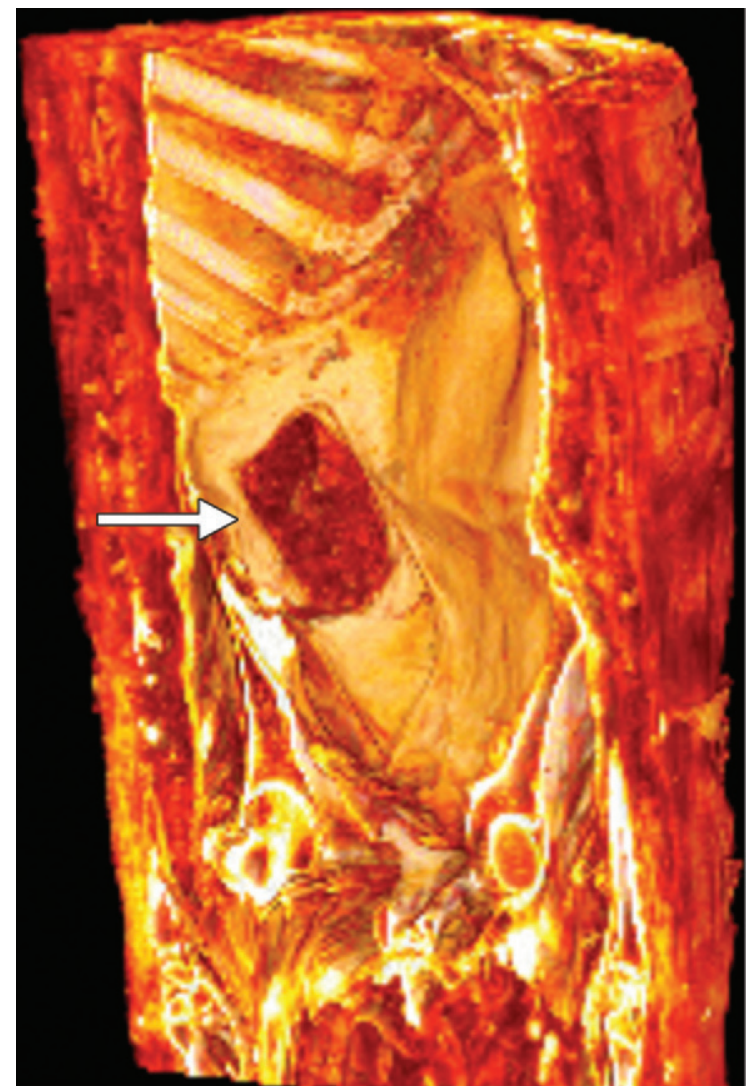

a.

Figure 3. (a, b) Posterolateral (a) and lateral (b) 3D images from multidetector CT of RM2718 show defects due to transnasal excerebration (arrow in b) and transabdominal evisceration (arrow in a). (c) Axial CT image shows a desiccated heart (arrow) within the pericardial sac.

RM2718 had been eviscerated through an 8.07-cm-long, 5.0-cm-wide, vertical incision in the left hypochondriac region (Fig $3 b$ ). The incision was in the form of a narrow oval with a circumference of approximately $20.8 \mathrm{~cm}$, a finding that might be indicative of an initial linear incision of approximately $10.4 \mathrm{~cm}$. This abdominal incision was not sutured, plugged, or covered with a plate.

The heart was intact within the pericardial sac (Fig 3c), but both lungs had been removed at a level just inferior to the carina. The diaphragm was absent, but it may have been damaged during a turn-of-the-century autopsy in which the abdominothoracic cavity was disrupted (see the section on "Disease and Postmortem Damage in RM2718"). The stomach, intestines, liver, and, possibly, urinary bladder were absent from the abdominal cavity. The dependent por-

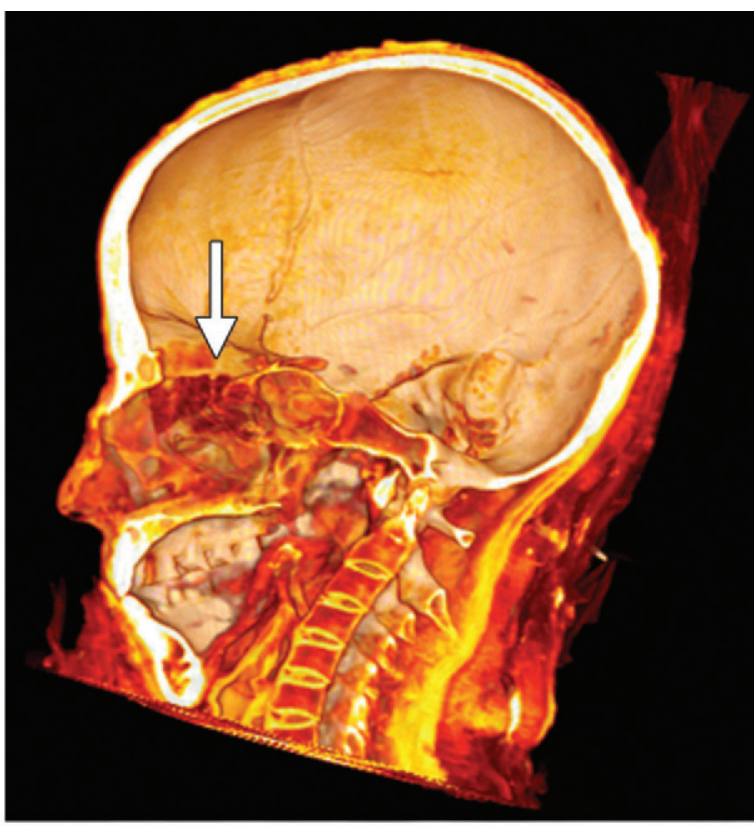

b.

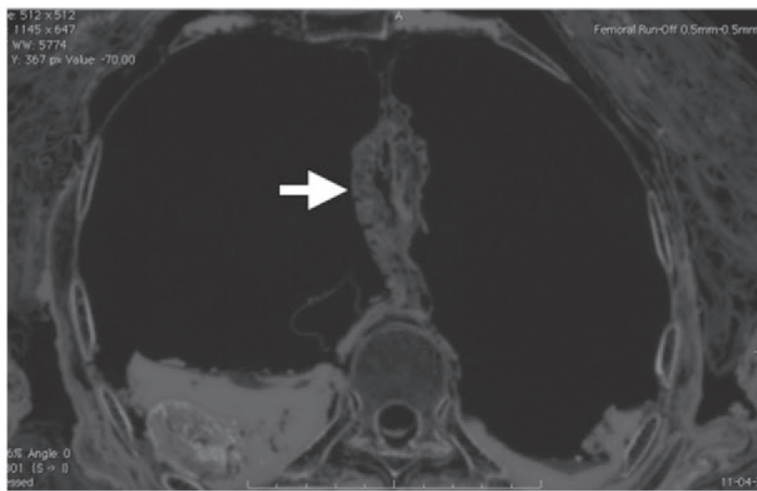

c.

tion of the thoracic cavity had been filled with resin, to a greater depth in the right hemithorax $(3.5 \mathrm{~cm})$ than in the left $(1 \mathrm{~cm})$. There was some unidentified debris on the surface of the resin in the right hemithorax, and a large piece of resin $(1.9 \times 1.6 \times 3.0 \mathrm{~cm})$ had broken off and lay at the lateral right surface.

One complete packet (possibly linen packing material or a wrapped organ), two fragmentary packets, and a void indicative of the absence of a fourth packet were seen in the resin. The whole packet, which was seen in the right hemithorax at the level of the T7 to T10 vertebrae, had a heterogeneous appearance with a low-attenuation core (range, -120 to $60 \mathrm{HU}$ ) and a high-attenuation margin and inclusions $(650 \mathrm{HU})$. Two partial packets, largely lost to autopsy damage, were present in the left hemithorax. The superior packet, which extended from T9 to T10, was a low-attenuation (-600 HU), slightly heteroge- 

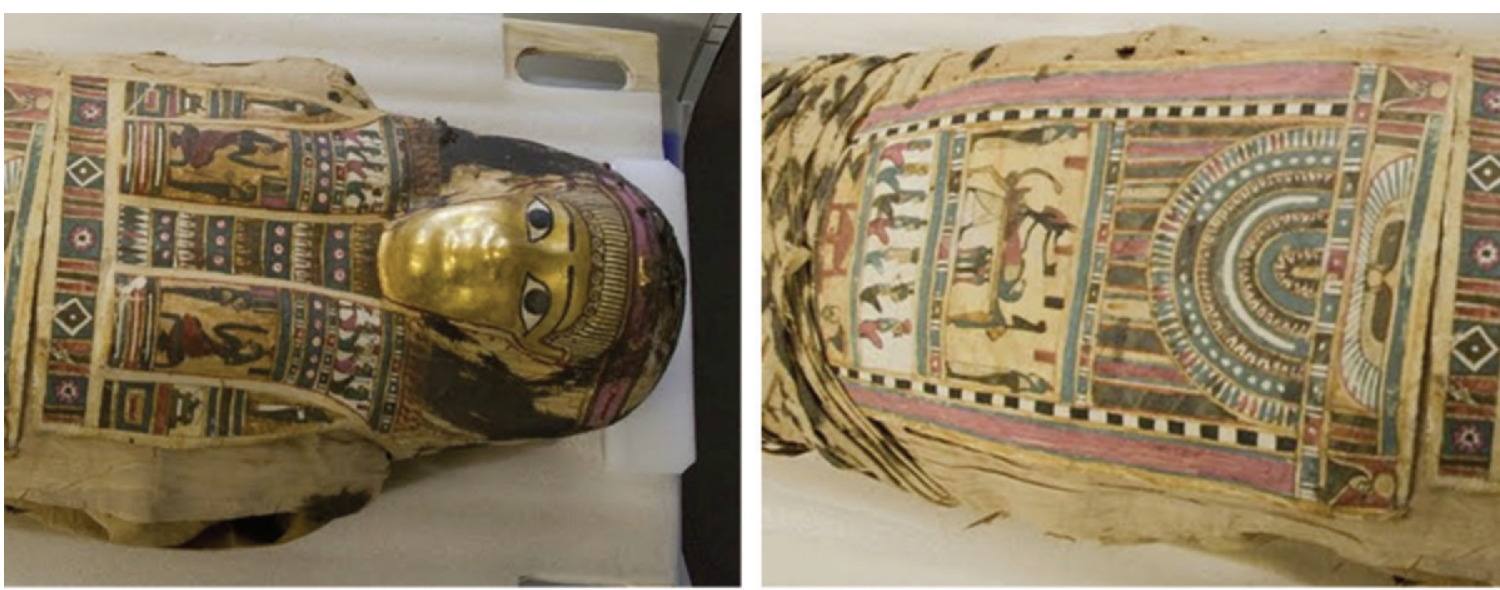

a.

b.
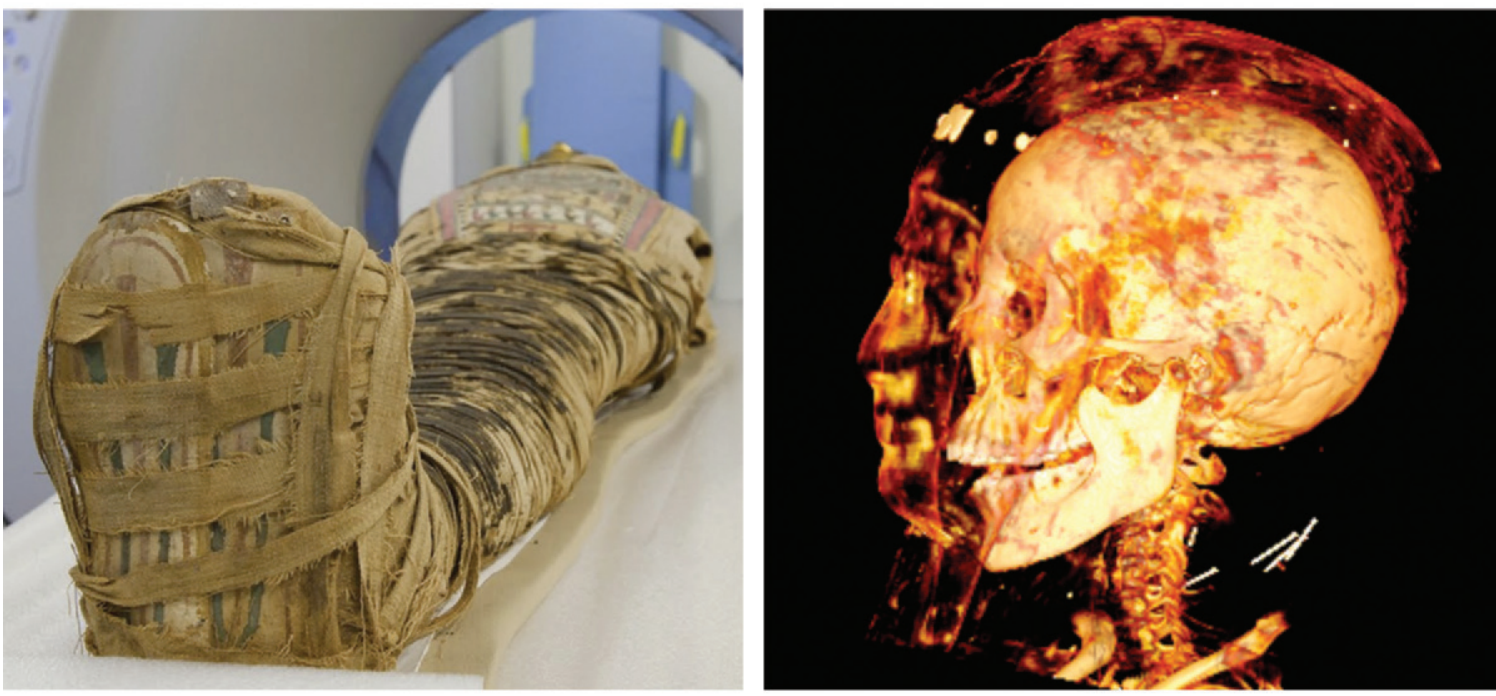

c.

d.

Figure 4. (a-c) Photographs show the highly decorated cartonnage encasing RM2720, including a gilded face mask (a), body case (b), and plaques at the soles of the feet (c). (Courtesy of Nicolas Morin, McGill University, Montreal, Quebec, Canada.) (d) Lateral 3D CT image, obtained with a window level of $651 \mathrm{HU}$ and a window width of $1000 \mathrm{HU}$, shows the mummy's skull and mask, with bright yellow-tan areas representing highly attenuating structures (skeletal bones, gold overlay and plaster ornamentation) and red and black areas representing areas of lower attenuation.

neous structure that had been folded in half. The second fragmentary packet, which extended from $\mathrm{T} 11$ to $\mathrm{T} 12$, had an appearance similar to that of the packet in the right hemithorax. In addition, a large void or depression in the resin within the left hemithorax, extending from $\mathrm{T} 7$ to T9, was believed to represent another packet that had been lost. Trailing resin-soaked linen that extended outward from the perineal region likely represented an anal tampon.

\section{Mummification of RM2720}

RM2720 was mummified anthropogenically and wrapped in three successive levels of linen bandages with a layer of resin or plaster and numer- ous small, high-attenuation inclusions between the levels. A crisscross pattern of thicker bandages (linen folded over two or three times) secured the outermost layer of linen wrappings. The head and chest were covered by a mask that consisted of cartonnage (plastered papyrus). The mask surrounded the head and separated the shoulders; the part that covered the face had been gilded, and eyes and brows had been painted on the surface (Fig 4a). The gilded portion, which has slightly higher attenuation on 3D images than does the surrounding part of the mask, likely consists of gold leaf, as it appears to the naked 
eye. Studs and the Wadjet eye (eye of Horus) on the forehead of the mask have marked high attenuation (range, 1200-1400 HU) and likely consist of solid plaster that was applied to the cartonnage surface (Fig $4 \mathrm{~b}$ ). A rectangular cartonnage plaque carries on where the mask ends, covering the anterior surface of the body to the level of the middle thigh (Fig 4c). A flat, foot-shaped cartonnage plaque had been placed beneath the sole of each foot and was held in place by the outermost layer of bandages (Fig $4 \mathrm{~d}$ ). The arms of the mummy were folded across the chest, the right arm over the left, with the left hand resting palm down on the right shoulder and the right hand resting palm down on the left upper arm (midshaft of humerus). Both the arms and legs were wrapped individually.

The mummy's brain and dural membranes (including the falx cerebri and tentorium cerebelli) were absent, but the dural sheath of the spinal cord was apparent at the foramen magnum. The brain had been removed via a transnasal craniotomy performed through the right ethmoid air cells, posterior vomer, superior right nasal concha, and anterior sphenoid bone (superior margin of the sella turcica). The left ethmoid air cells, orbits, and remaining nasal conchae were intact. A single pour of resin had filled the dependent eighth of the cranium (Fig 5a). Three small osseous fragments in the resin and two more in the superior spinal canal likely resulted from damage to the paranasal structures during mummification. A small amount of resin in the right ethmoid air cells was probably deposited there when resin was poured into the cranium. The source of resin seen in the left maxillary sinus was unclear but was likely also to be runoff from the cranial pour. The eyes remained intact in the orbits, and dense heterogeneous packing material (perhaps mud) was visible in the oropharynx and laryngopharynx. A folded and rolled dense linear object that was thought to be resin-soaked linen was present in the anterior portion of the oral cavity.

Three linear opacities, one in the craniotomy defect and two extending from the surface of the resin inferiorly and anteriorly through the foramen magnum to the $\mathrm{C} 3$ vertebra, were also noted (Fig 5b). The objects had attenuation of $130 \mathrm{HU}$, slightly lower than that of resin $(150 \mathrm{HU})$, and were clearly separable from the resin. With an appearance similar to that of a shed broom fiber, these objects might represent splinters or fragments from a wooden embalming tool.

RM2720 had been eviscerated through a large defect in the perineal region. Whether this was the result of a perineal incision or an anal or vaginal extraction that extended beyond its natural borders is not clear, but the single large plug of resin and linen that had been placed in the defect suggested that the defect was intentionally created by the embalmer.

The heart had been removed, leaving only an aortic remnant, and the left and right sides of the diaphragm had been incised to effect its removal. The lungs remained intact within the thoracic cavity (Fig 5c). The liver, stomach, intestines, and urinary bladder were absent from the abdominal cavity, and neither kidney was apparent in the retroperitoneal space. The skin of the abdomen has collapsed against the spine in the absence of the organs or any internal packing. A large heterogeneous mass or packet was positioned against the medial left thigh and extended from the groin along the superior third of the thigh. The contents of the packet were varied and included accumulations of particulate matter with attenuation ranging from 40 to $1000 \mathrm{HU}$ and a single hollow object resembling a seed pod or nut and measuring $7.2 \times 5.2 \times 6.5 \mathrm{~mm}$.

The oval object between the thighs was not an organ packet or papyrus scroll, but a torus of linen separating the distal thighs and knees. The packing between the upper thighs had a different texture and lower attenuation (range, -700 to $-400 \mathrm{HU}$ ). Its texture was finer, grainier, and less linear, and some parts exhibited a whorled pattern that was suggestive of wool or a similar animal-derived fiber. A much denser cloth was loosely bundled between the calves.

\section{Osteobiography of RM2717}

RM2717 is the mummy of a tall, upper-middleclass adult female. The obtuse subpubic angle and obtuse sciatic notch score (13) are strong indicators of female sex.

Epiphyseal fusion indicates an age of at least 20 years (range, $20-30$ years). The pubic symphysis morphology indicates an age of more than 25 years (mean age, 38 years) (14). The rib morphology indicates a greatest posterior probability of 50 years of age $(95 \%$ confidence interval $[\mathrm{CI}]$, 21-80 years; $50 \%$ CI, 39-61 years) (15). When considered together, these features place RM2717 between 25 and 80 years of age at her death. The
Teaching

Point 


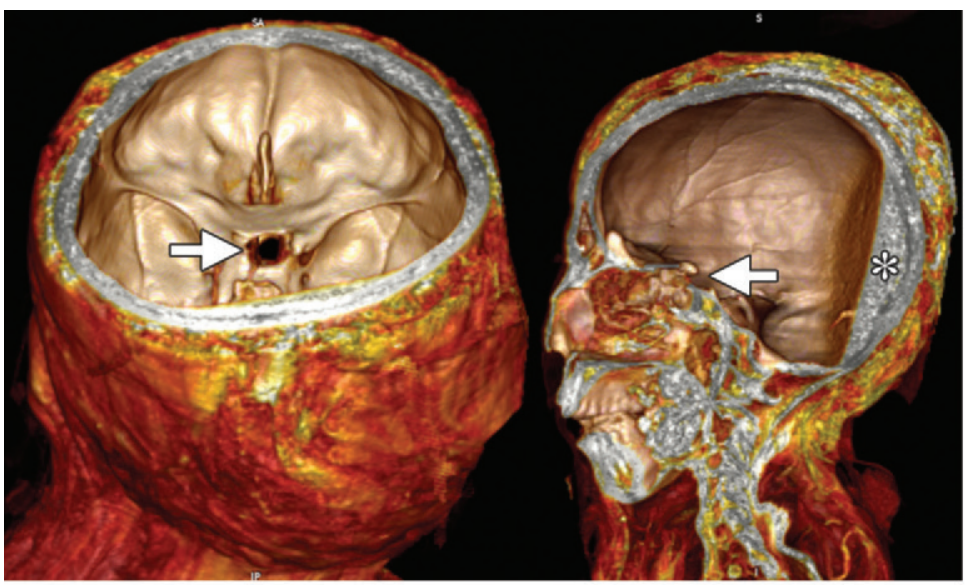

a.
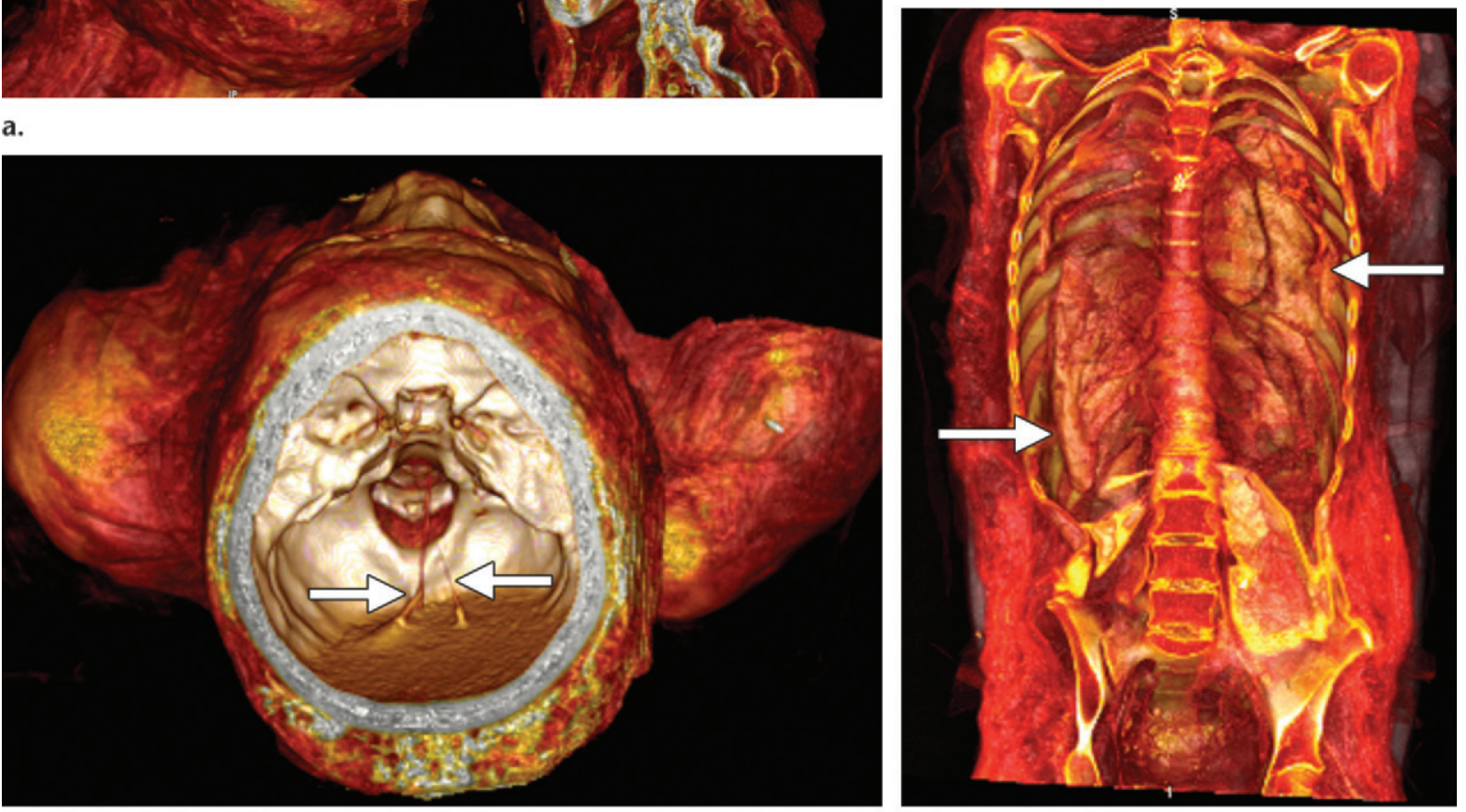

b.

c.

Figure 5. (a) Oblique superoposterior (left) and lateral (right) 3D CT images obtained in RM2720 show a transnasal route of excerebration (arrows) and resin deposited in the cranial cavity (*). (b) Oblique superior 3D CT image of the cranial cavity shows linear opacities (arrows) in the resin and foramen magnum. (c) Anterior 3D CT image shows intact lungs (arrows) within the thoracic cavity.

limited wear on her joints and the lack of vertebral osteophyte formation suggest an age at the lower end of this range, likely between 30 and 50 years. The diminished joint space and intervertebral disk opacification noted in the 1979 report are typical of Egyptian mummies and are the results of desiccation and postembalmment changes.

According to calculations based on the length of the long bones, the subject's height in life was approximately $160.9 \mathrm{~cm}$, or 5 feet 3 inches (range, 156.8-164.9 cm) (16). This is slightly greater than the mean height for ancient Egyptian women (157.5 $\mathrm{cm} \pm 5.2)$ (17). No Harris lines indicative of interrupted growth during child- hood were apparent on the CT scans, but such features may have been present and obscured by bone remodeling in adulthood.

The condition of the teeth of RM 2717 was poor. Only the left first and second incisors remained in the maxilla; an unresorbed socket for the right first incisor and a possible root fragment for the right second incisor were seen on CT scans. The mandible retained only the left and right incisors and canines and the right first premolar; the mandibular right first incisor was knocked inward toward the oral cavity. All the 


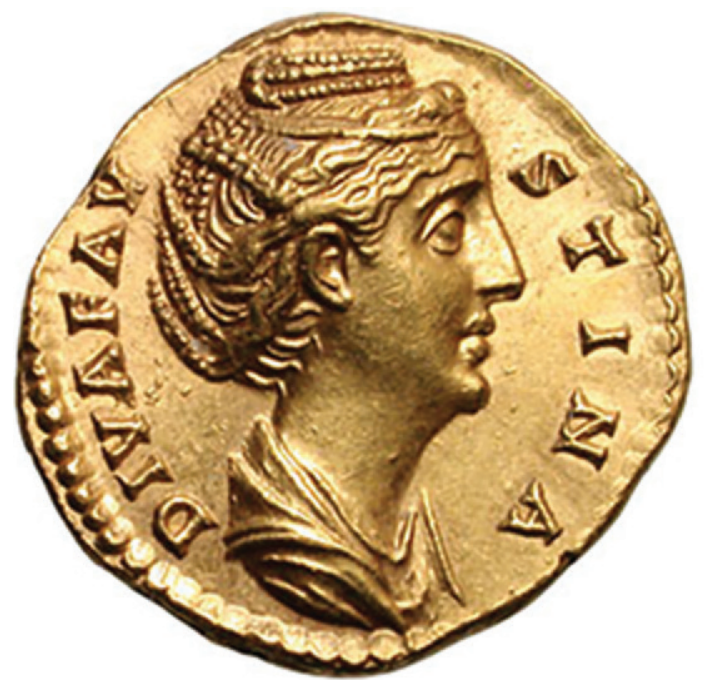

a.

Figure 6. (a, b) Photographs show a coin bearing the profile of Faustina I, the wife of Antoninus Pius (a), and a modern female subject (b), both wearing the same hairstyle as RM2720. (c) Lateral 3D CT image of the head of RM2720 shows the intersecting plaits of hair (arrowhead).

empty sockets, except those belonging to the right first incisor and a right mandibular molar (both of which were found to be loose in the oral cavity), had resorbed, findings indicative of extensive antemortem tooth loss. A large interproximal cavity was visible on the mesial surface of the mandibular right canine, and periapical abscesses were seen around the maxillary left incisors, mandibular left incisors and canine, and mandibular right second incisor, canine, and first premolar.

\section{Osteobiography of RM2718}

RM2718 is a young adult male, short in stature, and possibly of the elite classes. The presence of a penis and a narrow subpubic angle provide confirmation of male sex. Dental eruption and epiphyseal fusion patterns are indicative of skeletal maturity and, thus, a probable age of 20-30 years. Growth plate remnants indicate that maturity was achieved only a short time before death occurred. The pubic symphysis morphology indicates an age range of 19-34 years (mean, 23 years) (14). The rib morphology indicates an age range of $12-61$ years $(95 \% \mathrm{CI})$ or $18-36$ years $(50 \% \mathrm{CI})$, with a greatest posterior probability of 25 years (15). Overall, the skeletal features, including the absence of joint wear in the shoulders, hips, and

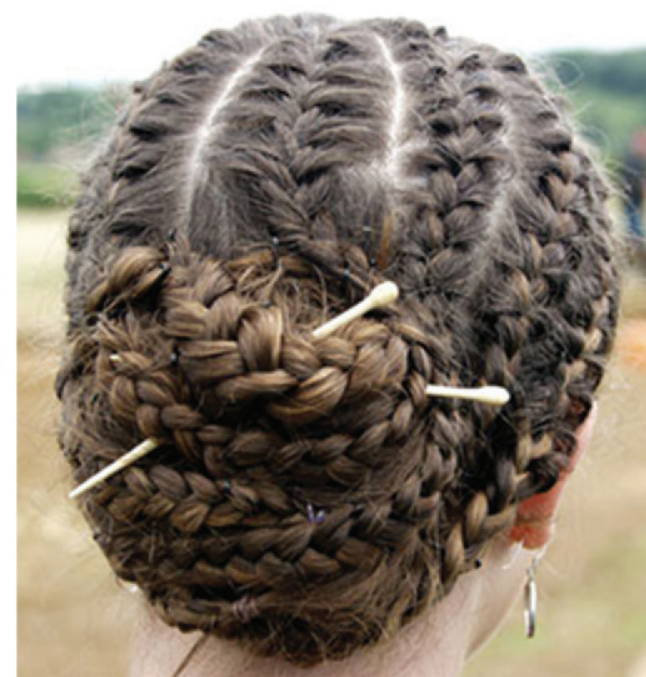

b.

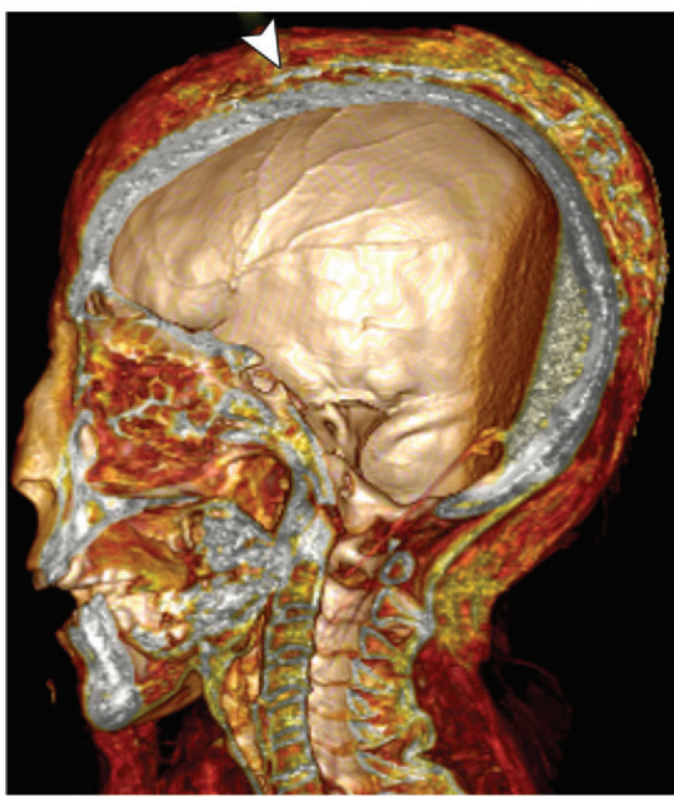

c.

knees as well as lack of vertebral osteophyte formation, help confirm an age range of 20-30 years at death. Incomplete sacral fusion is suggestive of an age at the lower end of that range.

According to calculations based on the length of the long bones, the subject's height in life was approximately $162.6 \mathrm{~cm}$ (range, $158.1-167.0 \mathrm{~cm}$ ), or 5 feet 4 inches (16). This is slightly shorter than the mean height for ancient Egyptian men (167.9 $\mathrm{cm} \pm 5.1$ ) (17). Faint Harris lines indicating interrupted growth during childhood are apparent in the distal and proximal tibiae.

The dental condition of RM2718 is mixed but poor overall. The mandibular dentition is in good condition, exhibiting only normal occlusal wear, 
whereas the maxillary dentition shows considerable degeneration. Maxillary periapical abscesses are apparent at the roots of the right first incisors, second premolar, and first molar, and of the left incisors and all three molars. There are large interproximal caries in the maxillary right first molar and left first and second molars, and a cavity in the lingual surface of the maxillary right second molar. A low-attenuation $(-260$ to $-120 \mathrm{HU}$ ) ball of homogeneous material in a left maxillary interproximal dental cavity probably represents an ancient treatment designed to protect the exposed nerve. Two maxillary premolars (right first premolar, left second premolar) are lacking, probably as a result of agenesis, according to the report from the previous dental examination (11), but the remains of a periapical lesion are present at the site of the maxillary right first premolar. There is also substantial wear on the labial surface of the left first and right second incisors, abutting the occlusal surface, a finding previously hypothesized to be due to dental fractures (11); however, the surfaces of the teeth are too smooth to make fracture a likely cause.

\section{Osteobiography of RM2720}

RM2720 is the mummy of a late-adolescent girl or young woman of average height and elite status. Female sex is strongly indicated by an obtuse subpubic angle; wide, shallow preauricular sulcus; and obtuse sciatic notch score (13). In addition, the mummy's hair is readily appreciable, with longer strands at the middle of the scalp drawn back into twists or plaits that were then wound into a tutulus, or chignon at the vertex (crown) of the head (Fig 6a, 6b). The individual plaits across the midscalp are readily apparent on axial and coronal CT scans. Sagittal 3D CT scans provide even more telling depiction of the hairstyle, because the nodes of hair commonly seen in plaiting are visible in cross section (Fig 6c).

The degree of epiphyseal fusion is indicative of recent skeletal maturity and suggestive of an age of 18-25 years. The pubic symphysis morphology indicates an age range of 15-24 years (mean, 19 years) (14). The rib morphology indicates an age range of $12-51$ years $(95 \% \mathrm{CI})$ or $12-23$ years $(50 \% \mathrm{CI})$, with a greatest posterior probability of 15 years (15). These features, along with complete dental eruption, help place the age of the subject at 18-24 years at the time of death.

According to calculations based on the length of the long bones, the subject's height in life was approximately $156.8 \mathrm{~cm}$ (range, 152.8-160.9 $\mathrm{cm}$ ), or 5 feet 2 inches (16). This is well within the average height range for ancient Egyptian females (157.5 cm \pm 5.2) (17). No Harris lines indicating interrupted growth during childhood are apparent on the scans.

The mummy's dental condition is excellent. All the adult teeth are present and show little wear. No caries or periapical abscesses were apparent at CT. The only noteworthy feature of dentition was misalignment of the mandibular left second incisor, which was twisted $90^{\circ}$ axially and displaced lingually behind the first incisor and canine.

\section{Social and Tem- poral Context of RM2717}

If the museum records are accurate and this mummy dates from the early years of the New Kingdom, the deceased is much more likely to have been a member of the elite than of the middle class; it was not until the end of the New Kingdom (in particular, the Third Intermediate Period) that mummification was democratized and the middle-class dead were anthropogenically mummified in substantial numbers (5). In addition, elite status has been attributed to all mummies in which evisceration was performed through a perineal incision, with one possible exception (the Royal Ontario Museum mummy ROM 910.5.3) (4). In addition, the height of RM2717 is greater than average, a finding that implies good childhood nutrition. The poor condition of the teeth of RM2717, considering the subject's advanced age at death and the highly abrasive grit in ancient Egyptian food, is an insufficient basis on which to definitively establish social status, although an elite diet would be expected to include finely ground or sifted flour. The inclusion of wood and spices in the wrappings, the woven fringe seen on some of the linen wrappings, and the presence of resinimpregnated linen or cartonnage pads on the body signal a mummification process that was somewhat more elaborate than the norm for a member of the middle class. However, the CT finding of an absent heart contrasts with the customary practice of heart retention during embalmment of deceased members of the elite in this period. This finding, along with the presence of stray twigs on the body and in the wrappings, could be associated with a lower social status (ie, middle class or lesser nobility). 


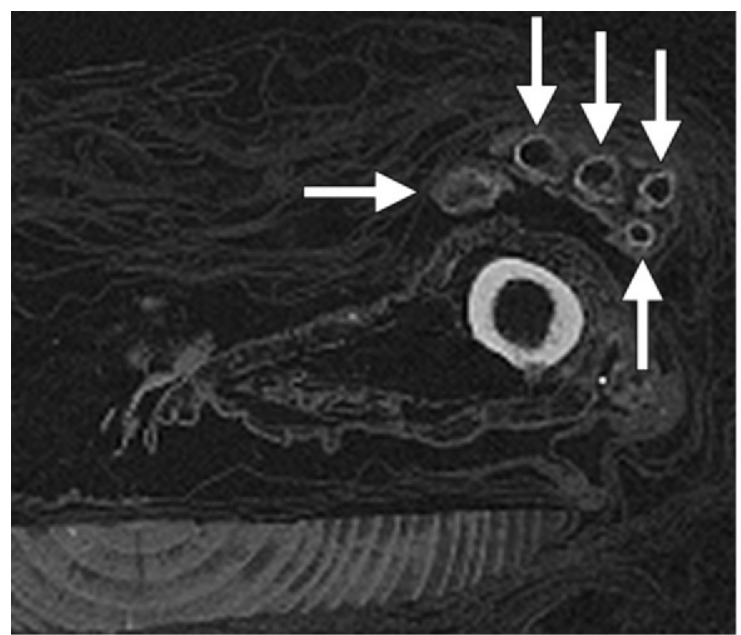

a.

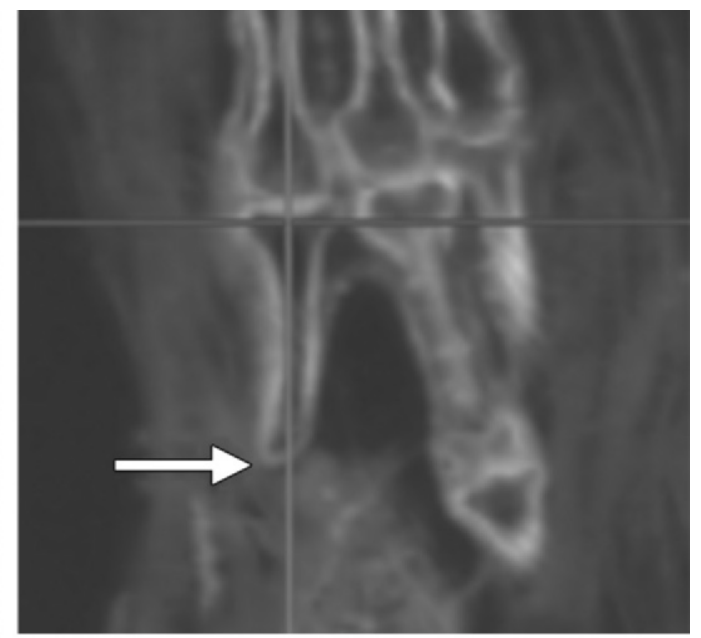

b.

Figure 7. Axial (a) and anterior oblique (b) CT images of the hands of RM2717 show the presence of all the left fingers (arrows in a) and the absence of the middle and distal phalanges of the right index finger with rounding of the proximal phalanx (arrow in $\mathbf{b}$ ). The wrappings appear to be intact.

\section{Social and Tem-}

\section{poral Context of RM2718}

The excellent preservation of the soft tissues and the inclusion of resin in the body cavity of this Theban male are suggestive of relatively high social status. However, the fact that the arms and legs are not wrapped individually or separately from the body indicates a less elaborate mummification procedure than is likely for a member of the elite. Considering the age of the subject at death, the mixed condition of the teeth (slight wear combined with evidence of dental repair) does little to clarify his social status. The presence of the intact heart within the pericardial sac is the strongest indicator of elite status. If the mummy dates from the New Kingdom, as has been hypothesized (10), the evidence of evisceration also would support an elite status association. However, the presence of packets in the thoracic cavity could be indicative of origin in a later period. If the remaining packets or those removed during the 19th-century autopsy are found to contain desiccated organs, a date subsequent to the 20th dynasty must be considered $(18,19)$.

\section{Social and Tem-}

\section{poral Context of RM2720}

The gilded mask and elaborately painted and decorated cartonnage of RM2720, the resin within the cranium, and the individual wrapping of the arms are indicative of more than the basic mummification treatment. The position of the arms, which are crossed right over left across the chest, is not an indication of elite or royal status but was the position preferred during the Ptolemaic period (20). The excellent condition of the woman's teeth is not a sufficient indicator of social status, considering her relative youth at death. The evidence of perineal evisceration during mummification, as for RM2717, may be indicative of elite status (4).

The mummy's hairstyle is suggestive of origin in the late Ptolemaic or early Roman period. This style was worn by Roman matrons throughout the Antonine dynasty (AD 96-192), but its popularity peaked among women in the Roman provinces during the reign of Antoninus Pius (AD 138-161), whose wife Faustina I may have established it as a fashion standard (21) (Fig 6a). In Roman Egypt during Antonine rule, a similar style was worn that consisted of short curls at the front of the head, with longer hairs twisted or plaited and joined in a tutulus at the vertex (22). By the time of Septimus Severus (AD 193-211), the most common hairstyle for Egyptian women included a central part at the midscalp and a twisted chignon at the neck (22).

\section{Disease and Post- mortem Damage in RM2717}

CT scans showed that the left little finger, which was reported in earlier studies to be missing, was actually tucked behind the ring finger and therefore not readily apparent on anteroposterior 


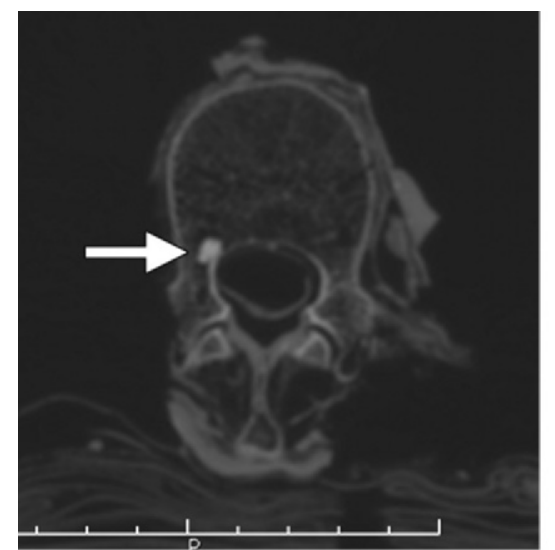

a.

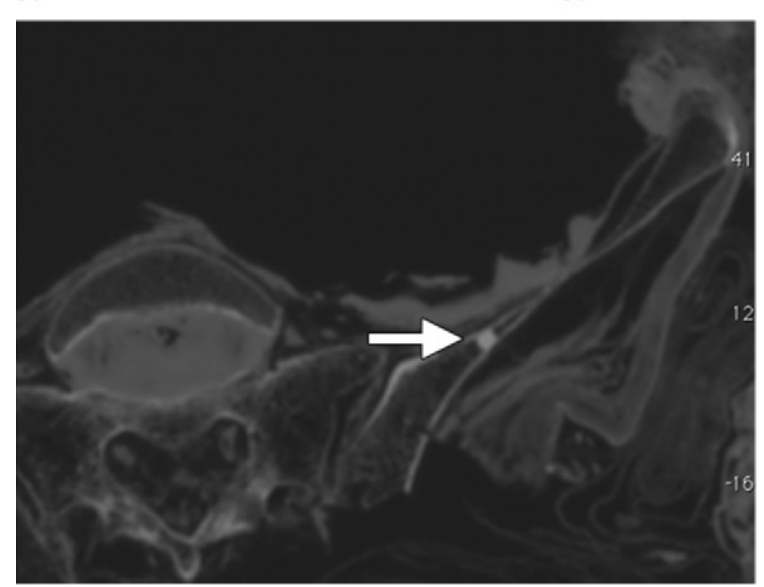

c.

radiographs (Fig 7a). Although the distal and middle phalanges of the right index finger were indeed missing, the wrappings around the finger were undamaged; thus, the loss of those finger segments occurred before death and mummification. The proximal phalanx had no distal articular surface and appeared rounded, a finding indicative of a well-healed antemortem injury (Fig 7b).

As previously mentioned, the feet and head of the mummy are unwrapped, and the remaining bandages are held in place at the shoulder with modern pins. The previously described spices on the face are no longer there, and only traces of the copper foil over the face and feet remain (6).

\section{Disease and Post- mortem Damage in RM2718}

The mummy was previously autopsied through a clean I-shaped incision in the back, running vertically from the T10 vertebra to the coccyx. Large sections of the original outer wrapping are missing and have been replaced with a more finely textured cloth that extends from the level
Figure 8. Axial CT images obtained in RM2718 show likely bone islands (arrow) in the L1 (a) and L4 (b) vertebrae, left ilium (c), and right ischium (d).

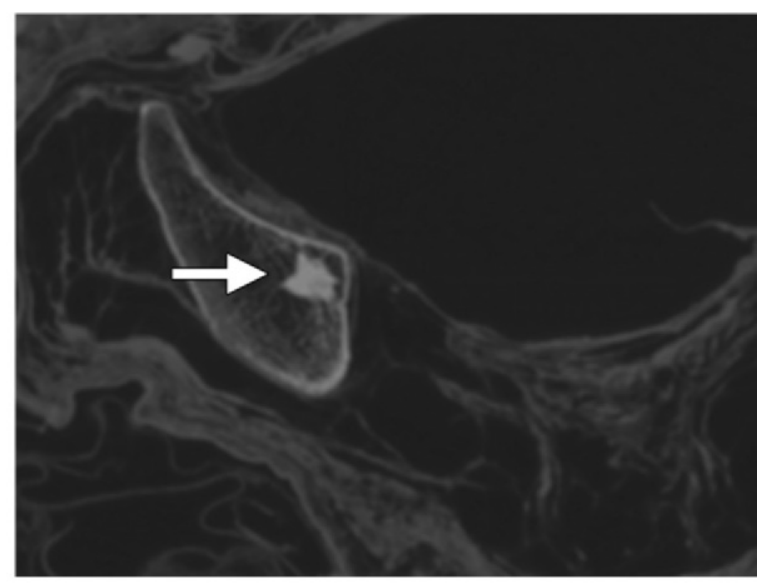

d.

of the L5 vertebra to a point beyond the coccyx, covering a body area that is $11.3 \mathrm{~cm}$ long, $9 \mathrm{~cm}$ wide (from left to right), and $2 \mathrm{~cm}$ thick (from anterior to posterior surface). Much of the back of the mummy, from the level of the T10 vertebra to that of L4 on the left side and L5 on the right side, is missing. The spine remains articulated, but the lateral processes of many vertebrae are damaged, having been cleanly excised. Both iliac crests, the ribs below T9, the left superolateral aspect of the sacrum (the S1, S2, and S3 vertebrae), and the left distal humerus are similarly damaged.

Small well-defined opacities, which are believed to represent bone islands, were observed in the right pedicle of the L1 vertebra and the left ilium (Fig 8a, 8b). Two larger homogeneous opacities with radial streaks, which were noted in the medulla of the right lateral margin of the L4 vertebral body and the right ischium, are also likely bone islands (Fig 8c, 8d). 

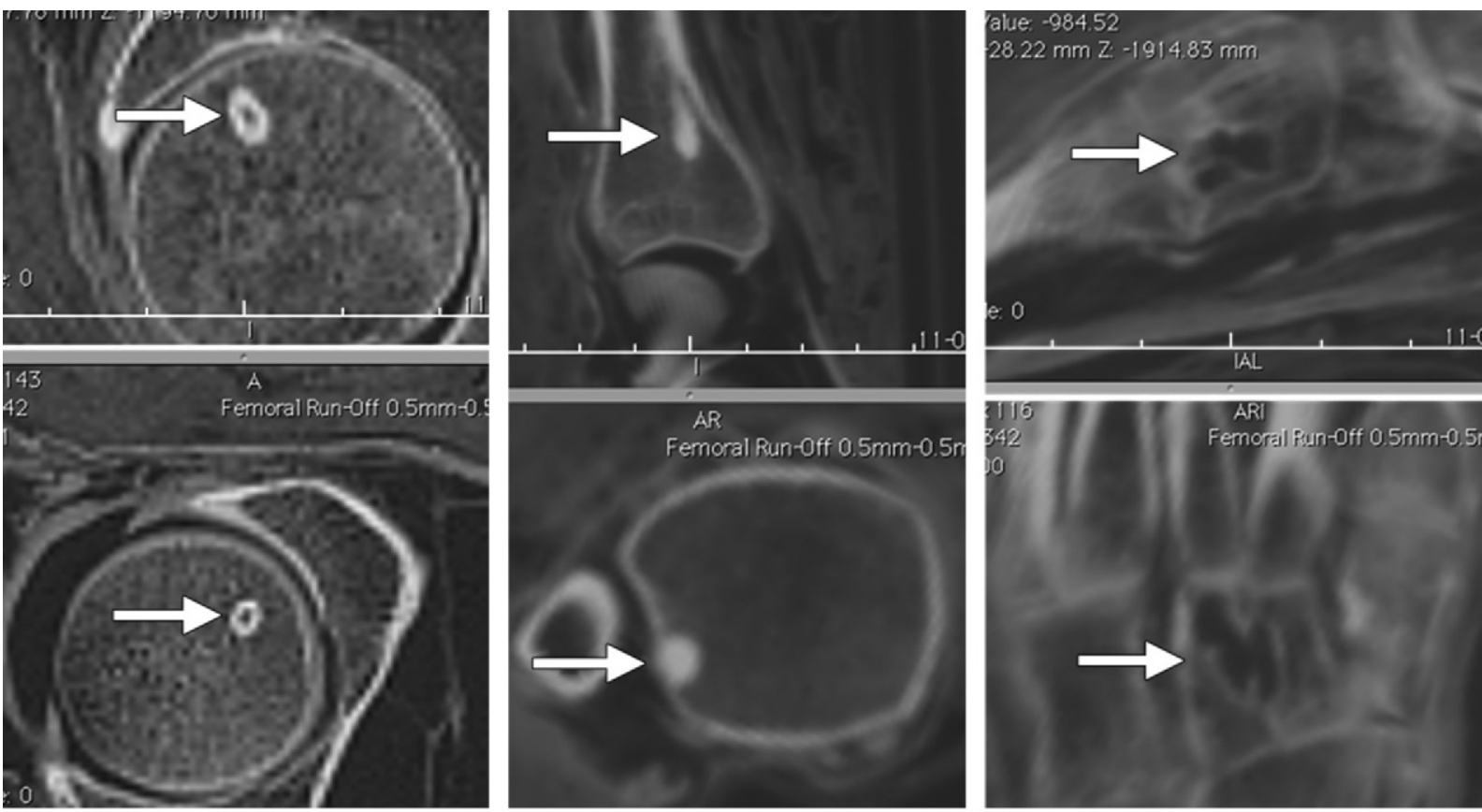

a.

b.

c.

Figure 9. Multiplanar reformatted images from multidetector CT of RM2720 show a small lytic focus with a sclerotic margin in the femoral head (arrows in a), a sclerotic lesion in the distal right tibia (arrows in $\mathbf{b}$ ), and a lytic lesion in the right lateral cuneiform bone (arrows in c).

\section{Disease and Post- mortem Damage in RM2720}

Several osseous and soft-tissue lesions were seen at CT. These lesions include several regions of slight, nonspecific subchondral sclerosis located bilaterally in the sacrum and ilium, superior and inferior to the sacroiliac joint, most notably in the inferior aspect.

A small (4-mm-diameter), spheroid, focal lytic lesion with a surrounding well-defined sclerotic margin was evident in the superomedioposterior portion of the right femoral head (Fig 9a). This lesion was believed to represent a geode that was healing at the time of death. Osteoid osteoma, Brodie abscess, small chondroblastoma, and eosinophilic granuloma were believed to be less likely alternatives.

A sclerotic lesion was observed in the diaphysis at the posterolateral aspect of the distal right tibia (Fig 9b). The lesion, which was proximal to the articulation of the tibia with the fibula and to the tibial growth plate remnant, extended $16.3 \mathrm{~mm}$ longitudinally, intersecting the cortex superiorly. No trabeculae were apparent within the lesion, and no periostitis was seen adjacent to it. The shape of the lesion was roughly circular $(4.9 \mathrm{~mm}$ in diameter) in the axial plane and cylindrical or teardrop-like in the longitudinal direction. The lesion was moderately well defined. A peripheral bone island was the favored diagnosis, but a healed fibrous cortical defect (nonossifying fibroma), healed incomplete fracture, healed infection, or atypical fibrous dysplasia could not be excluded.

Finally, a large lytic lesion was apparent in the inferior aspect of the distal one-fourth of the right lateral cuneiform bone (Fig 9c). The lesion was well defined and nonexpansile, with a sclerotic border, no periostitis, and slight cortical disruption that could represent postembalmment damage. The lesion was thought to be a large geode, intraosseous ganglion cyst, or simple bone cyst, but the differential diagnosis includes atypical infection as well as other benign types of lytic bone lesions (eg, aneurysmal bone cyst).

A group of three punctures was seen in the right side of the abdominal wall, each with a diameter of 3-4 $\mathrm{mm}$ and separated from the others by a distance of 5-10 $\mathrm{mm}$ (Fig 10). On the basis of the CT appearance of their margins, which were slightly thicker and showed higher attenua- 


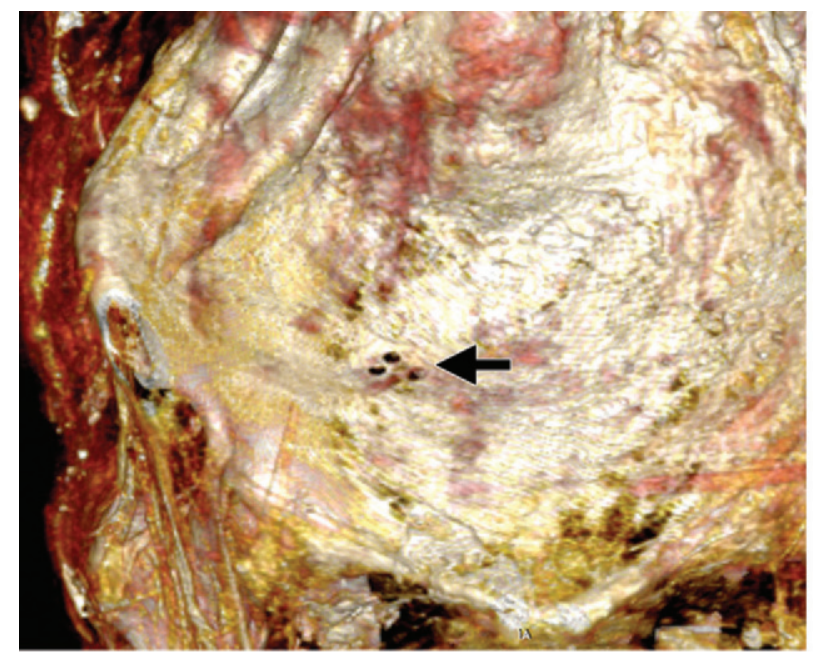

a.

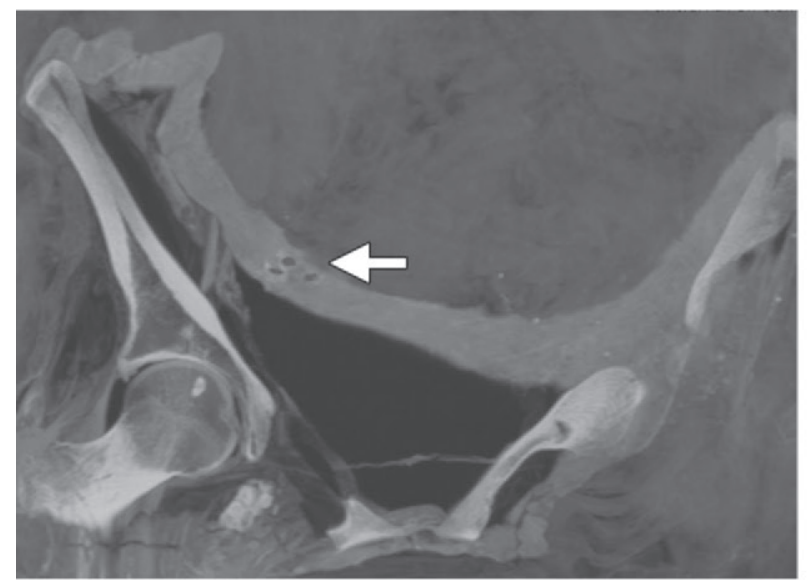

c.

tion than would be expected if the punctures had been created after mummification, these wounds were believed to have occurred either before or shortly after death. The thickness and density of the puncture margins may provide evidence of skin retraction under live tension as well as subsequent desiccation. Such punctures are not part of any known Egyptian mummification process; thus, although these CT findings are far from conclusive, it is possible that the punctures are related to the cause of death.

The wrappings across the mummy's face had been severed and the face exposed. The removal of wrappings, along with the presence of numerous modern pins at the posterior aspect of the neck and along the posterior right side, were indicators that the mummy had been unwrapped at some previous point, likely in modern times, and subsequently rewrapped.

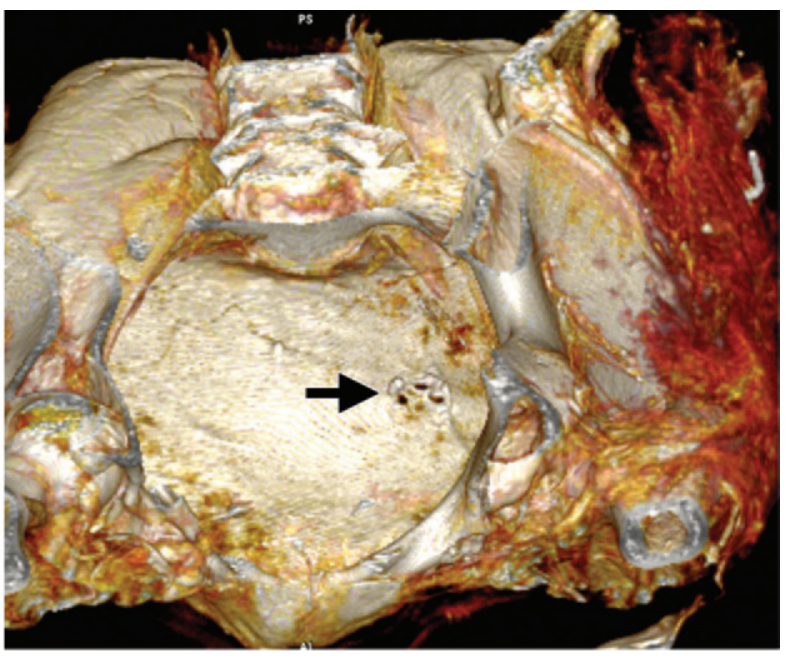

b.

Figure 10. (a, b) Three-dimensional CT images of RM2720 show a group of three abdominal punctures (arrow) from the exterior (a) and interior (b) surfaces. (c) Posterior oblique maximum intensity projection image shows high attenuation of the puncture margins.

\section{Conclusions and Future Directions}

Multidetector CT scanning at high resolution and with whole-body coverage not only provided new information about the particular mummies studied but also demonstrated a relatively uncommon example of heart retention, a rare case of lung retention with heart removal, and the unique and curious positioning of a cartonnage plaque over the left abdomen in a case of transperineal evisceration during mummification. These data expand the evidentiary basis for ongoing studies of the purpose and meaning of heart extraction and various evisceration and excerebration techniques used in mummification, as well as possible associations between specific mummification practices and sex, social status, time period, and geographic region.

Whereas the hairstyle of RM2720 helps confirm and narrow the time frame during which mummification likely occurred, the features of RM2717 and RM2718 are less definitively linked to a particular historical period. Radiocarbon dating studies of RM2717 and RM2718 are currently under consideration. If RM2717 dates from the New Kingdom, it provides an unprecedentedly early example of transperineal
Teaching Point 
evisceration, predating previous examples that reportedly date from the Third Intermediate Period (eg, 21st-dynasty mummy ROM 910.5.3, at the Royal Ontario Museum) (4).

The detailed examination of mummies has shed light on ancient and modern health, the history of disease and medicine, regional changes in mortuary rituals over time, and the interaction between personal identity and methods of mummification. Radiologic imaging has played an extremely important role and remains at the leading edge of technologic advances in the nondestructive analysis of mummies. The advances made in multidetector CT technology over the previous decade have been as essential to improving our understanding of the past as they have been to improving our health in the present.

Acknowledgments.-The authors thank the Montreal Neurological Institute and Hospital for providing access to their CT scanner; radiologic technologist Amélie Rouillard for her assistance in obtaining CT scans of the mummies described in this article; and CartGO Museological Services and Toshiba America Medical Systems, especially former account manager Salvatore Tucci and CT application specialist Annicka Cimbert of Toshiba, for assistance with study logistics.

\section{References}

1. Lewin PK, Harwood-Nash DC. X-ray computed axial tomography of an ancient Egyptian brain. IRCS J Med Sci Anat Hum Biol Biomed Technol Nerv Syst 1977;5:78.

2. Isherwood I, Jarvis H, Fawcitt RA. Radiology of the Manchester mummies. In: David AR, ed. The Manchester Museum Mummy Project. Manchester, England: Manchester Museum, 1979; 25-64.

3. Friedman SN, Nelson AJ, Granton PV, Holdsworth DW, Chhem R, Cunningham IA. Dual-energy computed tomography automated bone identification in ancient Egyptian mummies. In: Piombino-Mascali $\mathrm{D}$, ed. Yearbook of mummy studies. Vol 1. Munich, Germany: Pfeil, 2011;63-68.

4. Nelson AJ. Preliminary report on the radiographic analysis of three Egyptian mummies. Internal report for the Royal Ontario Museum. 2008.

5. Wade AD, Nelson AJ, Garvin GJ. A synthetic radiological study of brain treatment in ancient Egyptian mummies. Homo 2011;62(4):248-269.
6. Committee of the Natural History Society. Notes on Egyptian antiquities presented to the Natural History Society by Hon. Mr. Ferrier. Can Nat Geol 1859;4(6):401-403.

7. Zahn KA. The McGill University Egyptian mummy collection. In: Chadwick R, ed. Collected papers of the Society for Near Eastern Studies. Vol 2. Montreal, Canada: Society for Near Eastern Studies, 1984;25-29.

8. Braun SD. X-ray report. Redpath Museum internal report. 1979.

9. Sauneron S. Rituel de l'embaumement: pap. Boulaq III, pap. Louvre 5.158. Cairo, Egypt: Imprimerie Nationale, 1952.

10. Horne PD, Cardinal E. Report on the diagnostic imaging of the mummy Red-II with a summary report of the radiological findings. Redpath Museum internal report. 1995.

11. Langsjoen OM. The dental condition of Egyptian mummy Red-II based on non-destructive radiographic and C.A.T. diagnostic imaging technics. Redpath Museum internal report. [Undated.]

12. Gardner JC, Garvin G, Nelson AJ, Vascotto G, Conlogue G. Paleoradiology in mummy studies: the Sulman mummy project. Can Assoc Radiol J 2004; 55(4):228-234.

13. Buikstra JE, Ubelaker D. Standards for data collection from human skeletal remains. Fayetteville, Ark: Arkansas Archaeological Survey Press, 1994.

14. Brooks ST, Suchey JM. Skeletal age determination based on the os pubis: a comparison of the AcsádiNemeskéri and Suchey-Brooks methods. Hum Evol 1990;5(3):227-238.

15. DiGangi EA, Bethard JD, Kimmerle EH, Konigsberg LW. A new method for estimating age-at-death from the first rib. Am J Phys Anthropol 2009;138 (2):164-176.

16. Trotter M, Gleser GC. Estimation of stature from long bones of American Whites and Negroes. Am J Phys Anthropol 1952;10(4):463-514.

17. Zakrzewski SR. Variation in ancient Egyptian stature and body proportions. Am J Phys Anthropol 2003; 121(3):219-229.

18. Fleming S, Fishman B, O'Connor D, Silverman D. The Egyptian mummy: secrets and science. Philadelphia, Pa: University Museum, University of Pennsylvania, 1980.

19. Taylor JH. Death and the afterlife in ancient Egypt. Chicago, Ill: University of Chicago Press, 2001.

20. Gray PHK. Notes concerning the position of arms and hands of mummies with a view to possible dating of the specimen. J Egypt Archaeol 1972;58: 200-204.

21. Bartman E. Hair and the artifice of Roman adornment. Am J Archaeol 2001;105(1):1-25.

22 . Borg B. Der zierlichste anblick der welt: ägyptische porträtmumien. Mainz, Germany: von Zabern, 1998. 


\title{
Scenes from the Past
}

\section{Multidetector CT of Egyptian Mummies of the Redpath Museum ${ }^{1}$}

\author{
Andrew D. Wade, PhD • Gregory F. Garvin, MD • Faana H. Hurnanen, LicD • Lana Williams, PhD • Barbara \\ Lawson, $M A \cdot$ Andrew F. Nelson, PhD • Donatella Tampieri, $M D, F R C P(C)$
}

RadioGraphics 2012; 32:1235-1250 • Published online 10.1148/rg.324125704 • Content Codes: CT OT

\section{Page 1236}

The results of recent studies based on the Internet-based Mummy Picture Archive and Communication Technology (IMPACT) Radiological Mummy Database at the University of Western Ontario $(4,5)$ have underscored the importance of considering ancient Egyptian mummification techniques within a comparative context. The IMPACT Database, which consists of detailed descriptions and imaging studies in Digital Imaging and Communications in Medicine (DICOM) format, relies on contributions from interdisciplinary teams of scientific investigators and is designed to facilitate large-scale comparative studies based on primary data acquired with radiologic imaging.

\section{Page 1236}

These CT examinations were performed to help advance research into the variability of Egyptian mummification traditions over time and the sociopolitical forces driving the changes in ancient Egyptian mortuary ideology, as well as to validate findings in previous studies of these mummies.

\section{Page 1240}

The heart [of RM 2718] was intact within the pericardial sac, but both lungs had been removed at a level just inferior to the carina.

\section{Page 1242}

The heart had been removed [from RM 2720], leaving only an aortic remnant, and the left and right sides of the diaphragm had been incised to effect its removal. The lungs remained intact within the thoracic cavity.

\section{Page 1249}

Multidetector CT scanning at high resolution and with whole-body coverage not only provided new information about the particular mummies studied but also demonstrated a relatively uncommon example of heart retention, a rare case of lung retention with heart removal, and the unique and curious positioning of a cartonnage plaque over the left abdomen in a case of transperineal evisceration during mummification. 